\title{
Investigation of LEACH Protocol and its Successors in WSN
}

\author{
Er. Kiranpreet kaur \\ Research Scholar, DAV University, Jalandhar, India \\ E-mail: kiranlubana27@gmail.com \\ Er. Ridhi Kapoor \\ Assistant Professor, DAV University, Jalandhar, India \\ E-mail: ridhikapoor89@gmail.com
}

\begin{abstract}
Sensor nodes present in WSN plays its crucial role in sensing, processing and communicating data in brutal conditions. Power source like battery is required by these nodes for energy, which got sucked out in the processes like aggregation, compression and communication of sensed data. Extensive flaws seen now days are energy source constraints. After deploying nodes in nasty environment, worthwhile a battery is not rehabilitate. Therefore, proliferate usage of energy to enhance network lifetime is main issue. To clear up this trouble various clustering techniques are popularized. In clustering, sensor nodes group together to generate small clusters and $\mathrm{CH}$ is elected for aggregating data coming from cluster members. For large networks, hierarchical clustering model is applicable to assemble data at every cluster and transmit that processed data to the base station. This phase out repetitious data to be communicated which further curtail energy consumption. Various LEACH protocols are discussed in this review to enhance network lifetime.
\end{abstract}

Index Terms-Cluster-Head, Wireless Sensor Network, Base Station, Clustering, LEACH.

\section{INTRODUCTION}

WSN (Wireless Sensor Network) [12] is a system or a foundation that close detecting, preparing and correspondence (transmitter/recipient) components that gives ability to a gadget to screen and react the circumstances occurred in a particularized environment. The environment or condition can be physical or natural [10]. To gather the information from surroundings sensor hubs are utilized. As opposed to send crude information, sensor hubs utilize its handling limit and communicate just the appropriate or important information. [11] Now days, WSN faces a gigantic complexity of vitality requirement as limited battery lifetime. Every hub depends on vitality for preparing, collecting and discussing information with different hubs is a noteworthy concern [1]. With the utilization of an ideal directing techniques and bunching calculations [9] vitality devoured by correspondence process is actuated.
Every sensor hub assumes its fundamental part in various modes. In dynamic mode, hubs deplete vitality when gathering and broadcasting information. Out of gear mode, hubs ingest indistinguishable amount of vitality as in dynamic mode, though in rest mode hubs kill its radio to protect the vitality. Constrained vitality of sensor hubs confines the limit of hubs in the state of capacity, handling, memory and correspondence which prompts restricted lifetime of sensor system.

Clustering algorithms [9] assumes its basic part in decrease the vitality usage on the grounds that these calculations are exceptionally vitality viable rather than the immediate correspondence calculations. Little bunches are shaped with the coordination of sensor hubs for which the main hub i.e. $\mathrm{CH}$ (Cluster-Head) is resolved. Here, bunch individuals (i.e. hubs other than $\mathrm{CH})$ send information to their specific bunch observing hub (i.e. $\mathrm{CH}$ ) which also cumulate information and logically sends to the base station.[10] Cluster individuals or group hubs exchange its detected information to a short sweep inside their bunches, thus little amount of vitality is exhausted by sensor hubs show inside the group however higher amount of vitality is depleted when information is transmitting everywhere separate i.e. from CH (Cluster-Head) to BS (Base Station) [11]. A sensor hub is a constituent of substantial system of sensors. Every sensor exhibit in WSN has duty of social affair information from environment and sends that assembled information to the base station or processor [7]. Following Fig. 1 shows the sensor node structure with its components.

1) Sensors: These are little gadgets utilized for detecting physical perspectives from the topographical range in which they are appropriated. Sub units of detecting units are [6] sensors and ADC (Analog to Digital Converter). In light of occasions that are occurred in the encompassing condition, a simple signs are created by the sensors. [10] Sensors are use to gauge temperature, stickiness, weight, commotion level, attractive flux, warm rate, rubbing and so on.

2) Power Source: Power source is exceptionally basic for sensor organize lifetime. Every sensor 
hub is gathered with power supply. Vitality vault can be accomplished by energy components, batteries or different motors [11]. Distinctive wellspring of vitality are piezo-electric impact, vibrations, sun oriented power and so forth. Presently day's exploration stage centered on batteries which straight the node size.

3) Communication elements: Radio transmitter and radio receiver are primary components. Both are need for each node so that every node can speak with another node. Like RF (Radio Frequency) gadgets handset unit might be dynamic or latent. [16]Majority inclination is given to RF (Radio Frequency) correspondence since recurrence reusability is higher with the short separation and furthermore bundles move is little in size.

4) Processor: Flash Memory and Microprocessor is required by sensor nodes. Handling of gathered information is a fundamental capacity of preparing unit. At the point when entire data is gathered by the handling unit, the information is encased in the bundles. For broadcasting, these bundles are sent to the radio. All nodes can make a correspondence interface with a processor [10].

Staying substance is sorted out as takes after: Section II concentrates on grouping in WSN with the properties of bunch, group head abilities and bunch head decision criteria. Related work with respect to bunching conventions is appeared in segment III. Grouping based progressive directing convention i.e. Drain is characterized in segment IV. In segment $\mathrm{V}$ a diagram of successors of LEACH is given. In area VI, table of investigation of different LEACH conventions is characterized. Segment VII delineates conclusion with future degree.

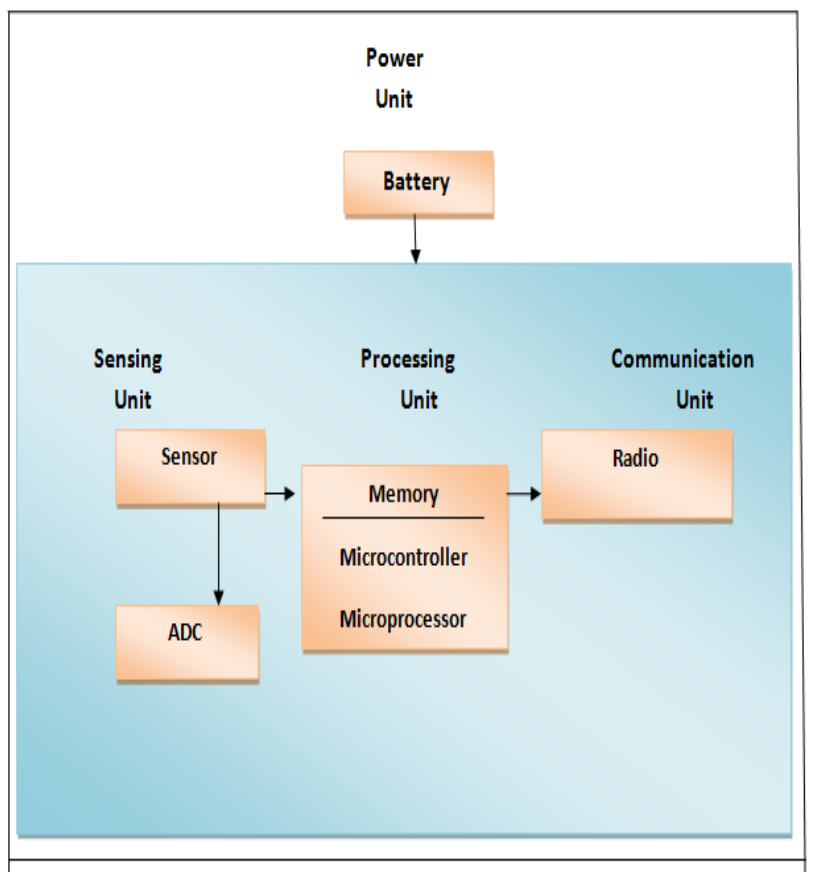

Fig.1. Architecture of sensor nodes with its Components

\section{CLUSTERING IN WSN}

Control usage is a basic viewpoint in WSN in which low vitality imperative is material on sensor nodes. After totally waste of batteries, dangerous issue emerges to recuperate or reestablish the sensor hubs. For extending life time of system power utilization ought to be play down. Today analysts target is to limit control utilization in WSN. Grouping conveyed a thought to reduction vitality utilization from sensor arrange.

Two level hierarchies are seems to be seen in clustered nodes network:

1) Lower level: At this stage sensor nodes transfer their data to the leading $\mathrm{CH}$ periodically.

2) Upper level: Here $\mathrm{CH}$ node collaborated data comes from lower level, compress it and further transfers the non-redundant data to the BS (Base Station).

In WSN if every one of the nodes are conveying and transmitting information at the same time then an unplanned impact, blockage, parcel misfortune and quick loss of vitality can happens. This issue is understood by satisfactory asset usage through various leveled bunching. With the lessening in the information transmission between bunch nodes and base station group versatility is improved. In progression, each bunch has its chief (known as $\mathrm{CH}$ ) and others that take after their specific executive are called group individuals. [15] Data transmission from $\mathrm{CH}$ (Cluster Head) to BS (Base Station) can be happens either in single jump or multi bounce. Huge amount of vitality is depleted at $\mathrm{CH}$ when information transmission can happen for far separation. Pivot of $\mathrm{CH}$ assumes a urgent part for balance out vitality in WSN through which better load adjusting can be involved. Base station is by and large undaunted and set inaccessible far from system. Information is drawn closer to the client from Base Station (handling point). [8] Role of middle of the road passage nodes between sensor nodes and BS (Base Station) is played by $\mathrm{CH}$ (Cluster Head).

\section{A. Cluster properties:}

For cause or produce bunches, grouping plans try to accomplish some embodiment. Such embodiment is applicable to the inside design of clusters or how it uncovers or relates with others. Likewise some consequent material certainties accessible as takes after:

1) Counting of clusters: CH's are prearranged or foreordained. $\mathrm{CH}$ choice can happens in a spontaneous way i.e. in irregular form by $\mathrm{CH}$ choice calculations from sent sensor nodes which turnout whimsical or variable number of clusters.

2) Topology inside cluster: Generally immediate correspondence can happens between cluster checking node (i.e. Cluster Head) and cluster individuals (i.e. cluster nodes with the exception of $\mathrm{CH}$ ), once in a while multi-jump can likewise assumes a key part through a middle of the road 
nodes.

3) $\mathrm{CH}$ communication with $\mathrm{BS}$ : Amassed information at $\mathrm{CH}$ node is exchange to the base station either in single hop or multi-hop with the participation of other cluster head nodes.

\section{B. Cluster Head efficiency:}

The succeeding components of cluster head nodes are particular elements between $\mathrm{CH}$ plans.

1) Mobility: $\mathrm{CH}$ may be immobile or movable. Sometime for enhancing the network performance, $\mathrm{CH}$ can move within a definite area.

2) Node Types: Sensor nodes may be homogeneous or heterogeneous in nature. In homogeneous, all nodes have same capacity such as composition or configuration, energy level, shape etc. whereas in heterogeneous nodes have dissimilar configurations.

3) Character or Role: Data aggregation, compression for removing repetitive data and relaying traffic are decisive role performed by $\mathrm{CH}$ node.

\section{Norms for CH selection:}

Guidelines used for selection of $\mathrm{CH}$ (Cluster Head) are:

1) Initial energy: When algorithm begins, all nodes are provided with an initial energy. Once the nodes are deployed, energy of nodes becomes variable. Nodes become dead when energy eats up completely by sensor nodes.

2) Left over or residual energy: On the basis of remaining energy of sensor nodes, the selection of $\mathrm{CH}$ (Cluster Head) can takes place after the accomplishment of some rounds.

3) Regular or average energy of network: Average energy is used as mention energy for every node. To keep network viable or alive this ideal energy is possessed by each node in current round.

4) Energy utilization rate: It is also a decisive criterion that compromises with the energy consumption rate. Node with higher energy among other nodes present inside a cluster would be elected as a cluster head.

\section{RELATED WORKS}

Gopi Saminathan Arumugam et al. [1] proposed EELEACH to enhance the network lifetime. To obtain the list of the nearby nodes sorting algorithms are performed. For the fusion of data, data ensemble can takes place. Residual energy plays a vital role for the optimal $\mathrm{CH}$ election. Through their proposed work package delivery was also improved.

Nishi Sharma et al. [2] analyzed the comparison of homogeneous and heterogeneous LEACH protocol on the basis of dead nodes, alive nodes and energy consumption by heterogeneous and homogeneous nodes. Capability of nodes is different in heterogeneous network in form of energy.

N. Sindhwani et al. [3] introduced V LEACH protocol in which vice cluster head plays the role of the cluster head when the cluster head dies. They evaluated that this protocol increased the network lifetime.

Renugadevi $\mathrm{G}$ et al. [4] proposed mobile LEACH for various mobile applications where nodes or sensors are mobile and moves at the particular velocity. They analyzed that with the mobility of nodes data availability rate becomes faster. They concluded that LEACH-M protocol performs better in terms of data package transmission rather than energy consumption.

A. Yektaparast et al. [5] proposed cell-LEACH which can extends the network lifetime on the basis of the residual energy. To balance the energy consumption, this protocol selects the cluster-heads on the basis of the residual energy.

Y.Lu et al. [6] proposed NEWLEACH protocol where nodes are chosen as cluster head on the basis of the residual energy and the distance between the nodes and the base station. They evaluated that this protocol extended the network lifetime.

S. Taruna et al. [7] proposed multi-hop clustering using gateway nodes in which data is transmitted from cluster-heads to base station through gateways using multiple hopping phenomenon. They analyzed that this methodology increases network lifetime.

V. Kumar et al. [8] analyzed the comparative study of various clustering protocols to form clusters for data fusion or aggregation which will further plays their vital role in prolonging network lifetime and lessen the energy consumption.Jianguangjia et al. [9] introduced EEACRA which made various improvements in terms of energy consumption. They introduced an energy weighted factor which furthers decreases the collision probability and hence network lifetime increases.

E.Abdellah et al. [10] introduced A-LEACH in which CAG nodes are work as a cluster head used to collect and aggregate the data and further transmit to the gateway or sink to minimize the energy consumption by the cluster head.

J.Zheng et al. [11] give their light shadow over the wireless sensor network concept. They analyzed how nodes or sensors are deployed in sensor network and what types of duties tey are performed.

Hamid Karimi et al. [12] introduced new clustering scheme for handling the failure or dead nodes in the real wireless sensor network. Through their work they concluded with their new clustering scheme dead nodes are decreased in the sensor network and hence network lifetime is increases.

Jorge Tavares et al. [13] analyzed various applications of wireless sensor network where sensors are used like to measure temperature, humidity etc. Different components of sensor network are also summarized in their work.

W.Heinzelman et al. [14] developed and analyzed the LEACH protocol in micro sensors network. They concluded that this protocol leaves beneficial results in 
terms of network lifetime, latency rate and application perceived quality.

I. Akyildiz et al. [15] and F. Akyildiz et al.[16] analyzed different types of wireless sensor networks in real world like terrestrial WSN, Multimedia WSN, Underwater WSN etc. They represented how the sensors are deployed and could sense their surrounding in these different sensor networks.

Table 1. Summary of some Clustering Protocols

\begin{tabular}{|c|c|c|c|c|c|}
\hline $\begin{array}{l}\text { Refere } \\
\text { nce no. }\end{array}$ & Author & $\begin{array}{c}\text { Paper title with } \\
\text { year }\end{array}$ & $\begin{array}{c}\text { Technique } \\
\text { Used }\end{array}$ & Advantages & Disadvantages \\
\hline [1] & $\begin{array}{l}\text { Arumugam et } \\
\text { al }\end{array}$ & $\begin{array}{l}\text { EE-LEACH : } \\
\text { development of } \\
\text { energy efficient } \\
\text { LEACH protocol } \\
\text { for data gathering } \\
\text { in WSN.(2015) }\end{array}$ & $\begin{array}{l}\text { EE-LEACH (Energy } \\
\text { Efficient Low Energy } \\
\text { Adaptive Clustering } \\
\text { Hierarchy) protocol }\end{array}$ & $\begin{array}{l}\text { 1) Enhance network lifetime } \\
\text { 2) Considerable amount of } \\
\text { energy is saved through data } \\
\text { ensemble. } \\
\text { 3) Better package delivery. }\end{array}$ & NA \\
\hline$[2]$ & $\begin{array}{l}\text { Nishi Sharma } \\
\text { et al. }\end{array}$ & $\begin{array}{l}\text { Energy Efficient } \\
\text { LEACH protocol } \\
\text { for wireless sensor } \\
\text { network. (2013) }\end{array}$ & $\begin{array}{lr}\text { LEACH } & \text { (Low } \\
\text { Energy Adaptive } & \text { Adustering Hierarchy) } \\
\text { Clustocol } & \end{array}$ & $\begin{array}{l}\text { 1) Fusion or aggregation cut } \\
\text { down the communication data. } \\
\text { 2) Minimize energy } \\
\text { absorption. }\end{array}$ & $\begin{array}{l}\text { 1) Randomly } \\
\text { election of } \mathrm{CH} \text {. } \\
\text { 2) Excessive } \\
\text { burden on } \mathrm{CH} \text { node for } \\
\text { removing redundancy in } \\
\text { data. }\end{array}$ \\
\hline [3] & $\begin{array}{l}\text { N. Sindhwani } \\
\text { et al. }\end{array}$ & $\begin{array}{l}\text { V LEACH: AN } \\
\text { Energy Efficient } \\
\text { Communication } \\
\text { Protocol for WSN }\end{array}$ & $\begin{array}{l}\text { V LEACH (Vice } \\
\text { cluster head Low } \\
\text { Energy Adaptive } \\
\text { Clustering Hierarchy) } \\
\text { protocol }\end{array}$ & $\begin{array}{l}\text { 1) Minimizes the burden of } \\
\text { cluster head. } \\
\text { 2) Increase the network } \\
\text { lifetime. }\end{array}$ & NA \\
\hline [4] & $\begin{array}{l}\text { Renugadevi G } \\
\text { et al. }\end{array}$ & $\begin{array}{l}\text { An analysis of } \\
\text { leach mobile } \\
\text { protocol for mobile } \\
\text { WSN (2013) }\end{array}$ & $\begin{array}{lr}\text { LEACH-M } & \text { (Mobile } \\
\text { Low } & \text { Energy } \\
\text { Adaptive } & \text { Clustering } \\
\text { Hierarchy) } & \text { protocol }\end{array}$ & $\begin{array}{l}\text { 1) Applicable for mobility } \\
\text { problems. } \\
\text { 2) Both } \mathrm{CH} \text { and cluster } \\
\text { member nodes are mobile in sensor } \\
\text { network. } \\
\text { 3) Successfully transmit the } \\
\text { packages. }\end{array}$ & $\begin{array}{l}\text { 1) Due to the } \\
\text { mobility of nodes and } \\
\text { extra control packets } \\
\text { excessive amount of } \\
\text { energy is lost. }\end{array}$ \\
\hline [5] & $\begin{array}{l}\text { A. } \\
\text { Yektaparast et } \\
\text { al. }\end{array}$ & $\begin{array}{lr}\text { An } & \text { Improvement } \\
\text { on } & \text { LEACH } \\
\text { protocol } & \text { (Cell- } \\
\text { LEACH) } & (2012)\end{array}$ & $\begin{array}{l}\text { Cell-LEACH (Cell } \\
\text { based Low Energy } \\
\text { Adaptive Clustering } \\
\text { Hierarchy) protocol }\end{array}$ & $\begin{array}{l}\text { 1) Lifetime of network is } \\
\text { extended through residual energy. } \\
\text { 2) No performance } \\
\text { degradation. }\end{array}$ & NA \\
\hline [6] & Y.Lu et al. & $\begin{array}{l}\text { Improvement of } \\
\text { LEACH in } \\
\text { Wireless Sensor } \\
\text { Networks based on } \\
\text { Balanced Energy } \\
\text { Strategy (2012) }\end{array}$ & $\begin{array}{lr}\text { NEWLEACH (NEW } \\
\text { Low r Energy } \\
\text { Adaptive Clustering } \\
\text { Hierarchy) protocol }\end{array}$ & $\begin{array}{l}\text { 1) Even distribution of dead } \\
\text { nodes balanced the energy in the } \\
\text { system. } \\
\text { 2) Prolong the network } \\
\text { lifetime. }\end{array}$ & NA \\
\hline [9] & $\begin{array}{l}\text { Jianguangjia } \\
\text { et al. }\end{array}$ & $\begin{array}{l}\text { An Energy-efficient } \\
\text { Adaptive } \\
\text { Clustering } \\
\text { Algorithm fouting } \\
\text { Wireless fonsor } \\
\text { Networks (2011) }\end{array}$ & $\begin{array}{lr}\text { EEACRA } & (\text { An } \\
\text { Energy } & \text { Efficient } \\
\text { Adaptive } & \text { Clustering } \\
\text { Routing Algorithm). }\end{array}$ & $\begin{array}{l}\text { 1) Node with more energy has } \\
\text { more chance to be a cluster head. } \\
\text { 2) Mechanism of minimum } \\
\text { energy cost reduces the energy } \\
\text { consumption of cluster head. }\end{array}$ & NA \\
\hline [10] & $\begin{array}{l}\text { E.Abdellah et } \\
\text { al. }\end{array}$ & $\begin{array}{l}\text { Advanced Low } \\
\text { Energy Adaptive } \\
\text { Clustering } \\
\text { Hierarchy (2010) }\end{array}$ & $\begin{array}{lr}\text { A-LEACH } & \\
\text { (Advanced } & \text { Low } \\
\text { Energy } & \text { Adaptive } \\
\text { Clustering } & \\
\text { Hoerarchy) } & \end{array}$ & $\begin{array}{l}\text { 1) Improves the stability. } \\
\text { 2) Decreases the probability } \\
\text { of failure nodes. } \\
\text { 3) Enhances the network } \\
\text { lifetime. }\end{array}$ & NA \\
\hline
\end{tabular}

\section{HIERARCHICAL RoUting PROTOCOLS BASED ON CLUSTERING}

\section{A. LEACH (Low \\ Energy Adaptive \\ Clustering} Hierarchy protocol):

It is conventional routing protocol which takes after circulated clustering algorithm methodology to upgrade organize lifetime by embracing the procedures like cluster head turn, information total and information combination strategies. [5] $\mathrm{CH}$ is chosen arbitrarily for better usage of vitality. By taking after the standard of closeness, ordinary nodes join their particular $\mathrm{CH}$. Cluster part nodes sense the encompassing information and transmit it to $\mathrm{CH}$ [14]. The $\mathrm{CH}$ hub totals information, then packs it to expel excess from information and further exchange it to the processor or sink (i.e. Base Station).

Leach increases network lifetime by: 
1) Minimizing energy absorption.

2) Fusion and aggregation to cut back communicating data.

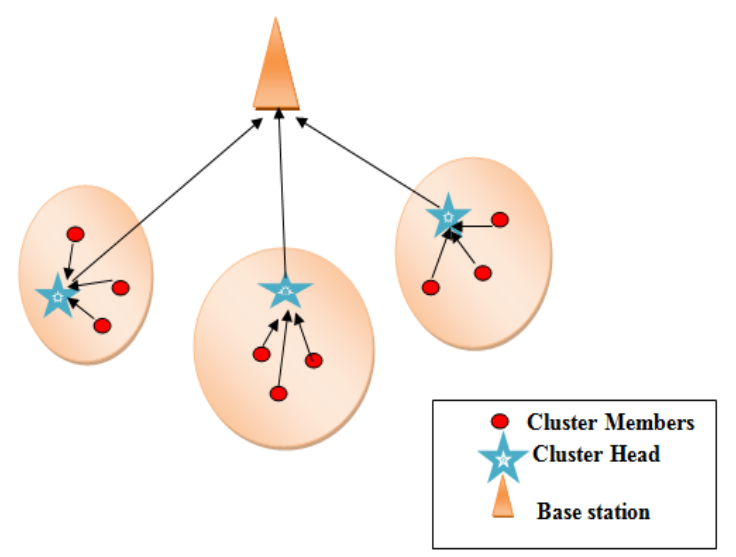

Fig.2. LEACH Cluster Formation

To achieve design goals duties are performed:

1) Cluster head should be movable randomly.

2) Local compression at $\mathrm{CH}$, global communication is curtailed.

3) Small energy radio approach

\section{B. PHASES OF LEACH:}

LEACH process deals with rounds and each round is accomplished through two phases:

1) Set-up phase: For each node random number (n) is generated between 0 and 1.If random number's value is smaller than threshold value given by threshold function $\mathrm{T}(\mathrm{n})$, that node would be selected as a cluster monitoring node.

$$
T(n)=\left\{\begin{array}{ll}
\frac{p}{1-p\left(r \bmod \frac{1}{p}\right)} & \text { n€ G } \\
0 & \text { Other }
\end{array}\right\}
$$

According to Eq. (1), p is cluster head probability. $G$ is set of nodes does not have any cluster head before $1 / p$ rounds. Later on when node selected as a $\mathrm{CH}$, through CDMA each cluster head node transmits information to nearby nodes to join neighboring $\mathrm{CH}$. $\mathrm{CH}$ node uses TDMA to provide message communication time.

2) Steady phase: This phase is for transmission of data, when cluster member nodes sense surrounding data and transmit to the particular $\mathrm{CH}$ (Cluster Head) in single hop [5]. Data aggregation and fusion is accomplished at $\mathrm{CH}$ later on this compressed data is send to base station.

\section{Flaws in conventional LEACH protocol:}

1) Arbitrary $\mathrm{CH}$ election: Each node have equivalent chance to be a $\mathrm{CH}$, this protocol does not consider residual energy fact to be a $\mathrm{CH}$ node. Data will be lost as soon if low energy node is selected as a $\mathrm{CH}$, because large amount of energy is consumed by this node which further decreases network life time.

2) Illogical allocation of $\mathrm{CH}$ : Energy capacity is imbalanced due to the random selection of $\mathrm{CH}$ node. Sometime very big and very small clusters are formed at a time because distance aspect is not in consideration while clusters formation [1]. More energy absorption can takes place, when large distance is present between $\mathrm{CH}$ and $\mathrm{BS}$.

3) Large burden on $\mathrm{CH}$ node: Data aggregation, data compression, data fusion and transfers the processed data to base station are essential responsibilities of $\mathrm{CH}$ [8]. To perform these duties efficiently huge amount of energy is drained at $\mathrm{CH}$. If $\mathrm{CH}$ node became dead, then cluster member nodes connected to it cannot work [3].

\section{SUCCESSORS OF LEACH PROTOCOL}

\section{A. LEACH-C (Centralized Low Energy Adaptive Clustering Hierarchy)-}

While correlating with the conventional LEACH, only variability in steady phase is seen. Duty of selecting $\mathrm{CH}$ is done by BS. Each node transmits its present location and energy level information to the BS. BS uses this universal information through GPS to form efficient clusters needed lesser communication. Only those nodes are chosen as a $\mathrm{CH}$ by base station which have large energy and this information is transfers to all other nodes [11]. Benefit of LEACH-C over Conventional LEACH is that it is deterministic approach of selecting number of $\mathrm{CH}$ which is preset while deployment of nodes. But LEACH-C does not possess robustness because it needed present location of each node through GPS.

\section{B. LEACH-F (Fixed number of cluster Low Energy Adaptive Clustering Hierarchy)-}

This protocol uses centralized approach similar to LEACH-C. Once the clustering is done, clusters are not again constructed in next round. $\mathrm{CH}$ are permanent and only mobility of $\mathrm{CH}$ within cluster is there. Its steady state is identical as classical LEACH protocol [2]. LEACH-F removes over head of re-clustering seen in basic LEACH as there are predetermined clusters are formed but this protocol not provides an adaptability of insertion or removal of nodes once the clusters are formed [5].

\section{LEACH-B (Balanced Low Energy Adaptive Clustering Hierarchy)-}

It follows decentralized approach in which each node knows its location coordinates and position of final destination irrespective of other nodes. Cluster formation, cluster head selection and data transportation with multiple approaches are the major roles of LEACH-B [8].Each node selects its cluster head on the base of 
energy exhausted within the way of source and sink.

\section{TL-LEACH (Two Level Low Energy Adaptive Clustering Hierarchy)-}

TL-LEACH follows multi-hoping instead of sending data directly to the base station like in LEACH protocol. The data aggregated by each cluster heads is further aggregates through another $\mathrm{CH}$ which exists in between these cluster heads plus base station, rather than directly transmitting data in the direction of base station [11].

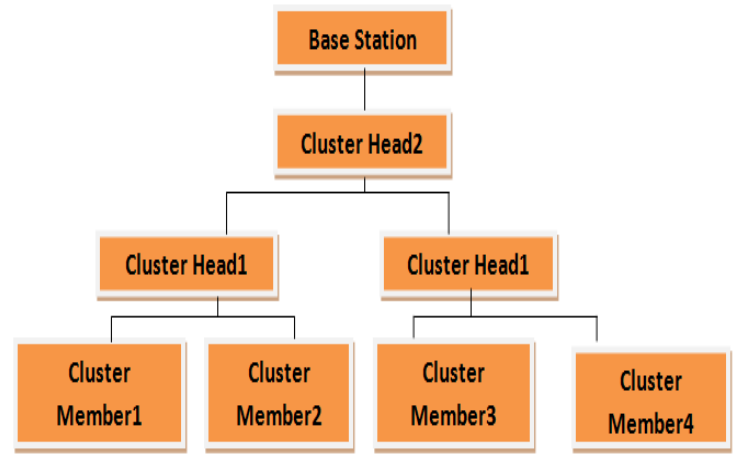

Fig.3. Hierarchy of TL-LEACH

TL-LEACH boosts energy capability with the use of intermediate relay node placed at the middle of other two cluster head nodes. This protocol cut down data transmission energy.

\section{E. LEACH-E (Energy Low Energy Adaptive Clustering Hierarchy):}

Initially, all nodes have same energy level and also got same chance to be a cluster head. Later on with the first round completion, nodes energy becomes variable. Then further cluster head node is selected on the base of the remaining or left energy [8]. Nodes with the highest residual energy over the other got preference to be cluster head over others. Equilibrium in energy load can be produced by LEACH-E protocol.

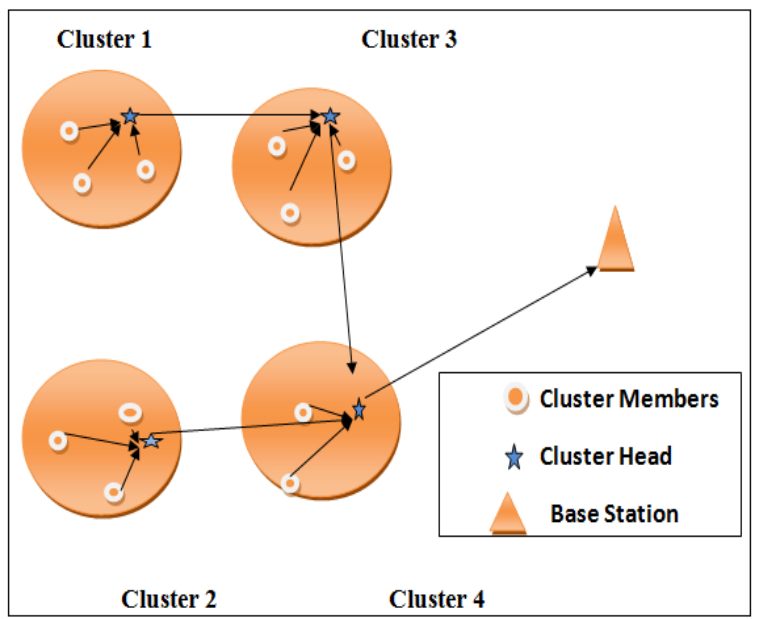

Fig.4. LEACH-E Protocol

F. MH-LEACH (Multi-Hop Low Energy Adaptive Clustering Hierarchy):
In LEACH, it is concludes that if BS is situated very distant away from sensor network then higher energy is depleted by $\mathrm{CH}$ while direct transmission from $\mathrm{CH}$ to BS. Distance between base station and cluster head is increases with an increase in the diameter of sensor network. Multi-hoping communication is proposed to raise energy effectiveness [10].

1) Firstly, cluster nodes transmit its surrounding data to the specific cluster head.

2) Later on $\mathrm{CH}$ transfers an accumulated data to other $\mathrm{CH}$ except direct forwarding data to the base station. An optimum way is followed by this protocol between $\mathrm{CH}$ and $\mathrm{BS}$.

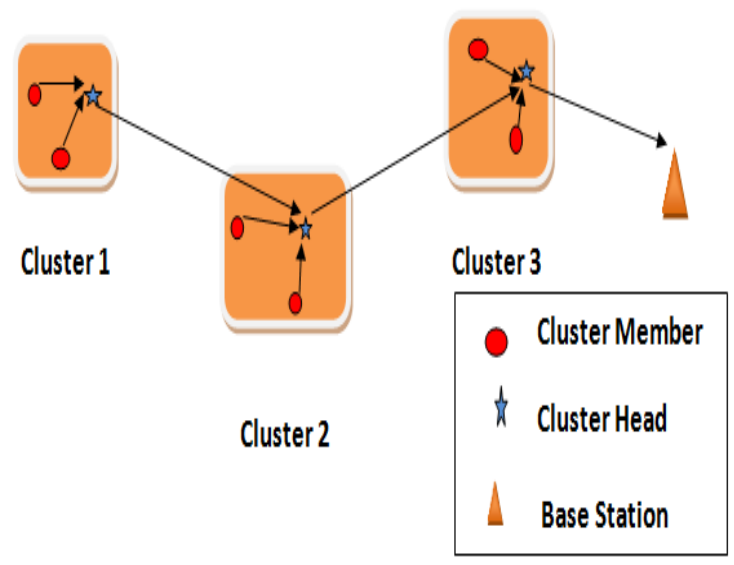

Fig.5. MH-LEACH Protocol

\section{G. $=M-L E A C H$ (Mobile Low Energy Adaptive Clustering Hierarchy):}

LEACH-M introduced for mobility problem. During set-up and steady phase this protocol provides mobility to both cluster monitor and cluster member nodes. Situated nodes are of identical capability and its location is determined through GPS. [4] Nodes with least mobility and minimum attenuation are elected as a $\mathrm{CH}$ node and advertisement message is transported through $\mathrm{CH}$ node to cluster member nodes present within communication range.

\section{H. I-LEACH (Improved Low Energy Adaptive Clustering Hierarchy):}

Activities of I-LEACH protocol are discovery of dual nodes and appointment of Sub-Cluster Head Nodes $(\mathrm{SCN})$. Dual nodes are the nodes which got higher chance of locating very near to one another when deployed in illogical manner (i.e. random fashion). Sleeping of one node is essential just before other is drained its energy. Hence, homogeneous or consistent allocation of cluster monitor is in I-LEACH protocol exhausted lesser energy when longer distance is to be covered [11].For directing normal nodes to every cluster head this protocol uses threshold access or approach.

I. A-LEACH (Advanced Low Energy Adaptive Clustering Hierarchy): 
Drawback of Conventional LEACH is that $\mathrm{CH}$ nodes eat up maximum energy than the normal nodes. Advanced LEACH is a heterogeneous protocol used for maximizing the stability period (i.e. Time interval before first node is dead) and to minimizes the chance of failing of nodes. Through synchronized clock each node knows the starting time of each round. Let ' $n$ ' is the sensor nodes count and ' $\mathrm{m}$ ' is the nodes having higher energy like $\mathrm{CH}$ or gateway nodes. Remaining $\mathrm{n} *(1-\mathrm{m})$ nodes are normal nodes $[1,4]$.

Benefits of A-LEACH are:

1) Cluster composition is free from base station.

2) Maximum energy admitted by $\mathrm{CH}$ on different levels of hierarchy is rescue by CDMA/TDMA approaches.

3) After failure of all normal nodes, CAG nodes (i.e. gateway nodes) still transmits data in the direction of base station.

Cluster 1

Cluster 2

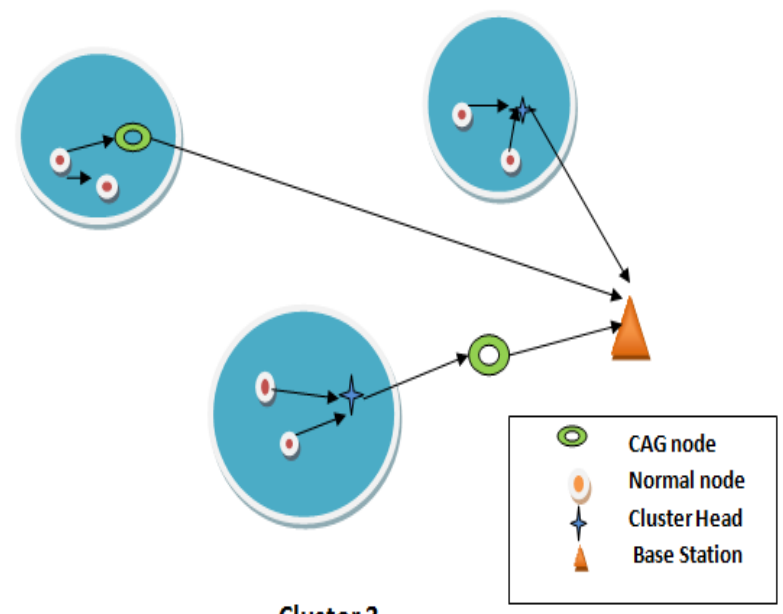

Cluster 3

Fig.6. A-LEACH Protocol

\section{J. Cell-LEACH (Cell Low Energy Adaptive Clustering Hierarchy):}

Here network is splits into the clusters which later on divided into the cells (comprises of seven hexagonal sections). $\mathrm{CH}$ is selected from different sensor present in every cell. Once the clusters are formed, no re-clustering can takes place. Using TDMA technique each sensor transfers data towards cluster head at its nominated time. Aggregation operation is executed by cell heads and processed data is transmitting to cluster head. $\mathrm{CH}$ accomplished the functionality of cell head and further transmits the processed data towards the base station [4].

\section{K. V-LEACH (Vice Cluster-Head Low Energy Adaptive Clustering Hierarchy):}

$\mathrm{CH}$ nodes dies earlier in conventional LEACH because $\mathrm{CH}$ consumes greater energy on comparing with the normal nodes due to the processes like data aggregation, data fusion as well as data compression is performed by
$\mathrm{CH}$ nodes drains huge energy. Also if $\mathrm{BS}$ is located very distant i.e. outside of network, then $\mathrm{CH}$ energy depleted rapidly and hence life of network decreases. This problem is solved by V-LEACH in which vice cluster head is introduced which plays the duty of $\mathrm{CH}$ when $\mathrm{CH}$ dies.

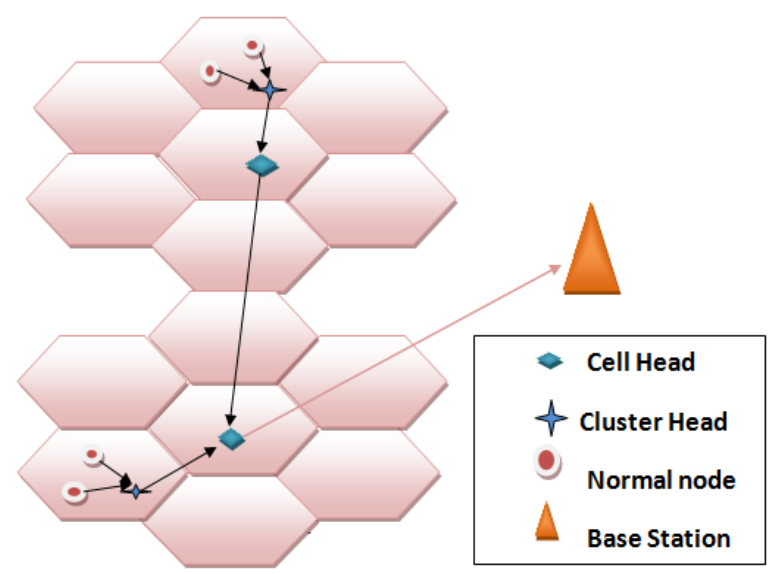

Fig.7. MH-LEACH Protocol

This protocol cut down the burden of selecting new cluster head when cluster head dies and its guarantees that data will definitely reach at the base station. Through this life of network is increase [2].

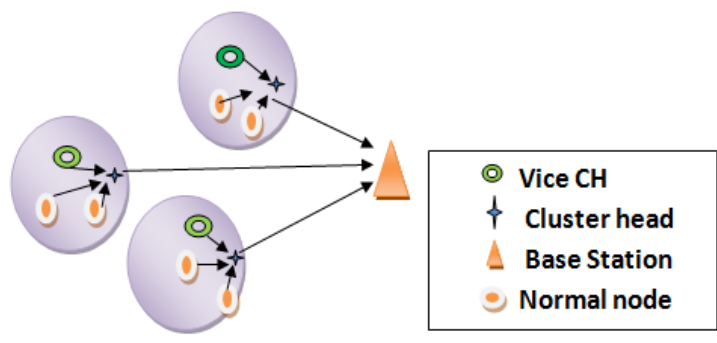

Fig.8. V-LEACH Protocol

L. EE-LEACH (Energy Efficient Low Energy Adaptive Clustering Hierarchy)-

Through Gaussian distribution, coverage probability is derived. Using residual energy sorting algorithm is executed. Here data ensemble can takes place which saves extensive energy when sink node is very distant away from the source node. Concept of residual energy is used to elect cluster head. This protocol improves the network lifetime and excellent packet distribution ratio [1].

\section{PERFORMANCE COMPARISON OF LEACH AND ITS DESCENDENTS}

A short analysis on classical LEACH and its successors in tabular manner in Table 2. 
Table 2. Performance Comparison between Various LEACH Successors

\begin{tabular}{|c|c|c|c|c|c|c|c|c|}
\hline $\begin{array}{l}\text { Clustering } \\
\text { Routing } \\
\text { Protocol }\end{array}$ & Year & $\begin{array}{l}\text { BS and } \\
\text { nodes } \\
\text { Mobility }\end{array}$ & $\begin{array}{c}\text { Self- } \\
\text { organized }\end{array}$ & Scalability & Distributed & Homogeneous & $\begin{array}{c}\text { Local } \\
\text { information } \\
\text { used }\end{array}$ & $\begin{array}{l}\text { Hop } \\
\text { count }\end{array}$ \\
\hline LEACH & 2002 & No & Yes & Limited & Yes & Yes & No & $\begin{array}{c}\text { Single } \\
\text { hop }\end{array}$ \\
\hline LEACH-C & 2002 & No & Yes & Good & No & Yes & Yes & $\begin{array}{c}\text { Single } \\
\text { hop }\end{array}$ \\
\hline LEACH-F & 2002 & No & No & Limited & No & Yes & Yes & $\begin{array}{c}\text { Single } \\
\text { hop }\end{array}$ \\
\hline LEACH-B & 2003 & No & Yes & Good & Yes & Yes & Yes & $\begin{array}{c}\text { Single } \\
\text { hop }\end{array}$ \\
\hline TL-LEACH & 2005 & No & Yes & Very Good & Yes & Yes & Yes & $\begin{array}{c}\text { Single } \\
\text { hop }\end{array}$ \\
\hline LEACH-E & 2007 & No & Yes & Very Good & Yes & NA & Yes & $\begin{array}{c}\text { Single } \\
\text { hop }\end{array}$ \\
\hline $\begin{array}{c}\text { MH- } \\
\text { LEACH }\end{array}$ & 2007 & No & Yes & Good & Yes & Yes & Yes & $\begin{array}{c}\text { Multi } \\
\text { hop }\end{array}$ \\
\hline LEACH-M & 2008 & Yes & Yes & Very Good & Yes & Yes & Yes & $\begin{array}{c}\text { Single } \\
\text { hop }\end{array}$ \\
\hline I-LEACH & 2009 & No & Yes & Very Good & Yes & Yes & Yes & $\begin{array}{c}\text { Single } \\
\text { hop }\end{array}$ \\
\hline LEACH-A & 2010 & No & Yes & Good & Yes & No & No & $\begin{array}{c}\text { Single } \\
\text { hop }\end{array}$ \\
\hline $\begin{array}{c}\text { Cell- } \\
\text { LEACH }\end{array}$ & 2012 & No & Yes & Very Good & Yes & Yes & Yes & $\begin{array}{c}\text { Multi } \\
\text { hop }\end{array}$ \\
\hline V-LEACH & 2013 & No & Yes & Very Good & Yes & Yes & Yes & $\begin{array}{c}\text { Single } \\
\text { hop }\end{array}$ \\
\hline EE-LEACH & 2015 & No & Yes & Very Good & Yes & Yes & Yes & $\begin{array}{c}\text { Single } \\
\text { hop }\end{array}$ \\
\hline
\end{tabular}

\section{CONCLUSION AND FUTURE SCOPE}

Vitality use is imperative worry in WSN, for augmenting lifetime of system. In this survey, LEACH convention is consider with its disadvantages and these downsides are toppled by successors of LEACH convention. Result of this audit is that for developing system lifetime there is still prerequisite of more steady, powerful and viable conventions in future.

\section{REFERENCES}

[1] Gopi Saminathan Arumugam, Thirumurugan Ponnuchamy. "EE-LEACH: development of energyefficient LEACH Protocol for data gathering in WSN."EURASIP Journal on Wireless Communications and Networking, 2015.

[2] Nishi Sharma, VandanaVerma."Energy Efficient LEACH Protocol for Wireless Sensor Network." International Journal of Information \& Network Security (IJINS) Vol.2, No.4, August 2013.

[3] N. Sindhwani and R. Vaid."V LEACH: AN Energy Efficient Communication Protocol for WSN." Mechanical Confab, vol. 2, no. 2, 2013.
[4] Renugadevi G, Smithra M.G."An analysis of leach mobile protocol for mobile WSN." International Journal of Computer Applications (0975 - 8887) Volume 65- No.21, March 2013

[5] A. Yektaparast, F.H.Nabavi, and A.Sarmast."An Improvement on LEACH protocol (Cell-LEACH)." International Conference on Advanced Communication Technology (ICACT), pp.992-996, 19-22, Feb. 2012.

[6] Y.Lu, D.Zhang, Y.Chen, X.Liu, and P.Zong. "Improvement of LEACH in Wireless Sensor Networks based on Balanced Energy Strategy." IEEE, International Conference on Information and Automation (ICIA), Shenyang, China,2012.

[7] S. Taruna, RekhaKumawat, G.N.Purohit. "Multi-hop clustering protocol using gateway nodes in WSN." International Journal of Wireless \& Mobile Networks (IJWMN) Vol. 4, No. 4, August 2012.

[8] V.Kumar, S.Jain, and S. Tiwari. "Energy Efficient Clustering gorithms in Wireless Sensor Networks: A Survey." International Journal of Computer Science Issues (IJCSI), vol. 8, issue 5, no. 2, September 2011.

[9] Jian-guangJia, Zun-wen He, Jing-mingKuang, and Cun-xiang Chen. "An Energy-efficient Adaptive Clustering Routing Algorithm for Wireless Sensor Networks." Cross Strait Quad-Regional Radio Science and Wireless Technology Conference (CSQRWC), 
vol.2, pp. 964-969, 26-30 July 2011.

[10] E.Abdellah, S. Benalla, A.B.Hsaane, and M. Lahcen. "Advanced Low Energy Adaptive Clustering Hierarchy." (IJCSE) International Journal on Computer Science and Engineering, vol. 02, no. 07, pp. 24912497, 2010.

[11] J.Zheng and A.Jamalipour. Wireless Sensor Networks: A Networking Perspective, Institute of Electrical and Electronics Engineers, 2009.

[12] Hamid Karimi, Mehdi Kargahi and Nasser Yazdani. "Energy-Efficient Cluster-Based Scheme for Handling Node Failure in Real-Time Sensor Networks."2009 Eighth IEEE International Conference onDependable, Autonomic and Secure Computing.

[13] Jorge Tavares, Fernando J. Velez, João M. Ferro. "Application of Wireless Sensor Networks to Automobiles." Measurement Science Review, Volume 8, Section 3, No. 3, 2008

[14] W.Heinzelman, A.Chandrakasan, and H.Balakrishnan, "An Application-Specific Protocol Architecture for Wireless Microsensor Networks," IEEE Transaction on Wireless Communications, vol. 1, no. 4, pp. 660-670, 2002.

[15] I. Akyildiz, W. Su, Y. Sankarasubramaniam and E. Cayirci, "Wireless sensor networks: a survey," Computer Networks,vol. 38,pp. 393-422, April 2002.
[16] F. Akyildiz, W. Su, (2002) "A survey on sensor networks", Communications Magazine, IEEE, vol. 40, no. 8 , pp.102-114.

\section{Authors' Profiles}

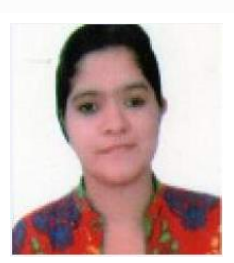

Er. Kiranpreet Kaur $\left(4^{\text {th }}\right.$ February, 1993). She has done B.tech-IT from DAVIET college (Jalandhar) and pursuing M.tech in CSE from DAV University, Jalandhar. She is a research scholar in CSE department and working in the domain of WSN.

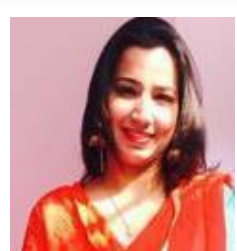

Er. Ridhi Kapoor $\left(4^{\text {th }}\right.$ December, 1989) She has done B.tech in CSE from PTU campus (Amritsar) and M.tech in CSE from GNDU campus (Amritsar). She has done her research in Distributed Databases and now working in the domain of WSN. She is working as an assistant professor in CSE department at DAV University

How to cite this paper: Er. Kiranpreet kaur, Er. Ridhi Kapoor,"Investigation of LEACH Protocol and its Successors in WSN", International Journal of Computer Network and Information Security(IJCNIS), Vol.9, No.6, pp. 44-52, 2017.DOI: $10.5815 / \mathrm{ij}$ cnis.2017.06.05 